\title{
La SEP impulsa desde 1984 la difusión y protección de la paleontología en España a través de diversas iniciativas
}

\author{
La Sociedad Española de Paleontología (SEP) desde su creación tiene como objetivos principales la \\ promoción y difusión de la paleontología a nivel científico y social, el apoyo a su enseñanza en todos \\ los ámbitos, así como la protección del patrimonio paleontológico. Agrupa a un número importante de \\ miembros que se reúnen anualmente en las Jornadas de Paleontología y cuenta con una revista científica, \\ Spanish Journal of Palaeontology, de ámbito internacional, que difunde contribuciones de las diversas \\ disciplinas paleontológicas.
}

\begin{abstract}
María José Comas-Rengifo | Dpto. de Geodinámica, Estratigrafía y Paleontología, Facultad de Ciencias Geológicas, Universidad Complutense de Madrid

Francisco J. Rodríguez-Tovar | Dpto. de Estratigrafía y Paleontología, Universidad de Granada

Ana Rosa Gómez Cano | Institut Català de Paleontologia Miquel Crusafont
\end{abstract}

URL de la contribución <www.iaph.es/revistaph/index.php/revistaph/article/view/4200>

El 19 de octubre de 1984 en el Museo Nacional de Ciencias Naturales de Madrid tuvo lugar una reunión científica a la que asistieron 36 paleontólogos de todo el país. En esta reunión se creó una comisión gestora de la Sociedad Española de Paleontología (SEP) y también se acordó la celebración de jornadas científicas periódicas, la creación de una revista y que la protección del patrimonio paleontológico sería una de sus funciones prioritarias. Dicha comisión gestora, formada por los doctores y doctoras Alberdi Alonso, Goy Goy, Granados Granados, Lamolda Palacios, Santafé Llopis, Sequeiros San Román y Truyols Santonja, fue la encargada de elaborar un proyecto de estatutos. Transcurrido un año, el 24 de octubre de 1985 se celebró en Zaragoza la asamblea constituyente de la Sociedad en la que se aprobaron los estatutos y fue elegida la primera junta directiva, cuyo presidente y vicepresidente fueron Truyols Santonja y Sequeiros San Román, respectivamente.

En la actualidad la SEP está presidida por M. José Comas-Rengifo, y Francisco J. Rodríguez-Tovar como vicepresidente, manteniendo el objetivo de la promoción y difusión de la paleontología y de las actividades relacionadas con ella, tanto en España como a nivel internacional. Así mismo, representa los intereses generales de carácter científico de la comunidad paleontológica

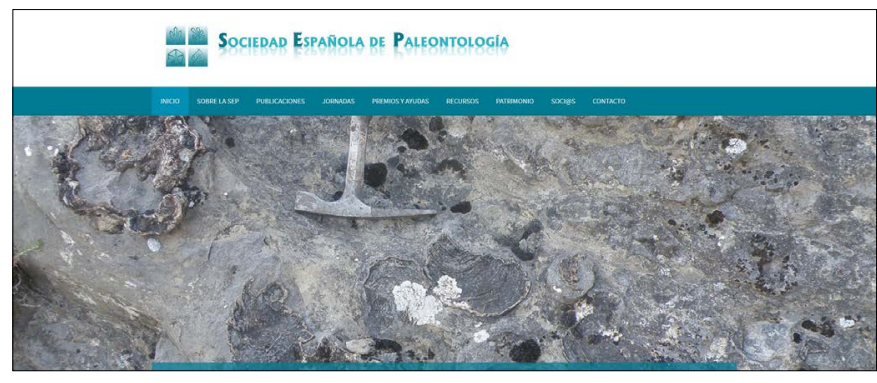

Web de la Sociedad Española de Paleontología (http://sepaleontologia.es/)

española ante las distintas administraciones con competencias en política científica o de gestión del patrimonio paleontológico. La protección de dicho patrimonio, a través del asesoramiento a los departamentos administrativos correspondientes, es una finalidad fundamental de la SEP.

La promoción cultural de la paleontología y el apoyo a su enseñanza en todos los ámbitos y aspectos posibles son objetivos primordiales de la Sociedad Española de Paleontología, además de facilitar su acercamiento a la sociedad, actuando como interlocutor científico de referencia ante las distintas administraciones en todo lo relativo al valor patrimonial y social de los fósiles y el conocimiento paleontológico. Esto se lleva a cabo mediante diversas actuaciones entre las que se incluyen 
el fomento de las relaciones científicas entre sus miembros a través de reuniones y publicaciones, y también de su página web, así como su incorporación en las redes sociales Facebook y Twitter.

Las jornadas de paleontología nacieron con el objetivo fundamental de ser el punto de encuentro de especialistas en los diferentes campos de la paleontología, de tal modo que constituyeran el foro de presentación, discusión e intercambio de conocimientos sobre las investigaciones desarrolladas. Las primeras tuvieron lugar en Zaragoza en el año 1985. A partir de esta fecha las sucesivas reuniones, realizadas con carácter anual y celebradas ininterrumpidamente, han contado con comunicaciones de contenido libre dedicadas a diferentes áreas de la paleontología, así como con trabajos sobre temas monográficos. Es importante resaltar que en ocasiones las jornadas han alcanzado un carácter internacional al desarrollarse en Portugal, como las XVI Jornadas que tuvieron lugar en Évora o las XXVI en Lisboa. También este año, las XXXIV Jornadas de Paleontología de la SEP coincidirán con el IV Congreso Ibérico de Paleontología y tendrán lugar en la Universidad de Trás-os-Montes e Alto Douro, en VilaReal (Portugal), siendo el tema monográfico los "fósiles y yacimientos paleontológicos ibéricos de relevancia internacional".

La SEP publica, desde su fundación en 1986, la revista Revista Española de Paleontología, actualmente Spanish Journal of Palaeontology (SJP), que difunde contribuciones científicas de las diversas disciplinas contenidas en la paleontología. Por lo que desde su constitución la SEP ha cumplido la mayoría de los objetivos propuestos, entre ellos la periodicidad de sus jornadas y la publicación de dos números de la revista al año.

El número de socios creció primero muy rápidamente y de los 36 asistentes iniciales se pasó a unos 100 socios en 1985, 304 en 1990 y 348 en 1995. Luego el crecimiento ha sido más lento y casi se ha estabilizado. En la actualidad la SEP cuenta con 332 miembros, de los cuales 7 son socios corporativos y 325 son socios ordinarios, de los que 30 son estudiantes menores de 27 años (12 hombres y 18 mujeres) y, entre los 293 socios restantes, 207 son hombres y 88 mujeres.
En su preocupación por apoyar la investigación de las y los jóvenes paleontólogos en cualquiera de las ramas o especialidades de la paleontología, la SEP convoca anualmente desde el año 2013, un programa de ayudas de investigación dirigidas a este colectivo. Hasta el momento se han concedido 31 proyectos cuyos interesantes resultados han sido publicados en nuestra revista. Con el mismo objetivo, se otorgan dos premios a las dos mejores comunicaciones presentadas en los encuentros de jóvenes investigadores en paleontología (EJIP) que se celebran de manera anual e ininterrumpida desde el año 2001.

La paleontología forma una parte esencial de los grados en geología y en biología de las universidades españolas y, a nivel de postgrado, se imparten estudios de máster en paleontología en la Universidad Autónoma de Barcelona, la Universidad Complutense de Madrid y la Universidad de Valencia.

En los últimos años, debido en parte a la crisis económica que ha afectado particularmente a los sectores jóvenes con puestos temporales en instituciones académicas e investigadoras, han surgido nuevas vías laborales para personas especializadas en paleontología. Este impulso se ha debido en particular a la creación de pequeñas y medianas empresas.

Cabe destacar la incorporación de profesionales al ámbito de la difusión y divulgación de la paleontología, lo que permite trasladar los conceptos de ciencias de la tierra y evolución adaptándolos a distintas necesidades educativas. Unidos al avance de la sociedad digital han surgido numerosos canales de divulgación de paleontología y se hacen necesarios profesionales que proporcionen y verifiquen estos contenidos. Además, son indispensables profesionales cualificados para realizar tareas de consultoría, seguimiento y prospección de obras ante la posibilidad de encontrar restos fósiles. En conclusión, es imprescindible contar con personas formadas en paleontología para preservar y poner en valor el patrimonio paleontológico. 